\title{
Both Immediate and Delayed Intracavernous Injection of Autologous Adipose-derived Stromal Vascular Fraction Enhances Recovery of Erectile Function in a Rat Model of Cavernous Nerve Injury
}

\author{
Xuefeng Qiu ${ }^{a, b}$, Thomas M. Fandel ${ }^{a}$, Ludovic Ferretti ${ }^{a}$, Maarten Albersen $^{a, c}$, Haiyang Zhang ${ }^{a}$, \\ Guiting Lin ${ }^{a}$, Ching-Shwun Lin ${ }^{a}$, Tania Schroeder ${ }^{d}$, Tom F. Lue ${ }^{a, *}$ \\ ${ }^{\text {a }}$ Knuppe Molecular Urology Laboratory, Department of Urology, University of California, San Francisco, CA, USA; ${ }^{\mathrm{b}}$ Department of Urology, Affiliated Drum \\ Tower Hospital, School of Medicine, Nanjing University, Nanjing, China; ${ }^{\mathrm{c}}$ Department of Urology, University Hospital Leuven, Leuven, Belgium; ${ }^{\mathrm{d}}$ American \\ Medical Systems, Minnetonka, MN, USA
}

\section{Article info}

\section{Article history:}

Accepted February 5, 2012

Published online ahead of

print on February 18, 2012

\section{Keywords:}

Cavernous nerve injury

Erectile dysfunction

Adipose tissue-derived stem

cells

Adipose-derived stromal

vascular fraction

Nerve regeneration

Radical prostatectomy

Penile rehabilitation

\begin{abstract}
Background: Intracavernous injection of cultured adipose-derived stem cells (ADSCs) effectively restores erectile function in cavernous nerve $(\mathrm{CN})$-injured rats when administered at the time of injury. However, culturing exposes ADSCs to the risk of contamination and dedifferentiation.

Objective: Explore the effect of uncultured autologous adipose-derived stromal vascular fraction (SVF) on improving erectile function in a rat model of $\mathrm{CN}$ injury when administered at the time of injury or $4 \mathrm{wk}$ after injury.

Design, setting, and participants: Eighty-nine male Sprague Dawley rats were randomly divided into four groups. CN injury or sham surgery was performed at the start of the study, and rats were treated with either SVF or vehicle. Functional testing and histologic analysis were performed $12 \mathrm{wk}$ after $\mathrm{CN}$ crush or sham surgery.

Intervention: We used intracavernous injection of saline immediately after $\mathrm{CN}$ crush $(n=23)$, intracavernous injection of SVF immediately after CN crush $(n=17)$, intracavernous injection of SVF 4 wk after CN crush $(n=23)$, or sham surgery $(n=26)$.

Outcome measurements and statistical analysis: We studied intracavernous pressure (ICP) response to $\mathrm{CN}$ electrostimulation and performed histologic examination of midpenile cross-sections. Data were analyzed using one-way analysis of variance followed by the Tukey-Kramer test.

Results and limitations: Both immediate and delayed treatment with SVF resulted in a significantly increased ICP-to-mean arterial pressure ratio compared with the vehicletreated group. Both immediate and delayed treatment with SVF significantly increased expression of neuronal nitric oxide synthase and neurofilament in dorsal penile nerves compared to the vehicle group. Furthermore, the smooth muscle-to-collagen ratio within the corpus cavernosum was significantly improved in both of the SVF groups compared to vehicle-treated rats. The main limitation of the study is the lack of determination of the SVF components.

Conclusions: Uncultured autologous SVF injected immediately or $4 \mathrm{wk}$ after $\mathrm{CN}$ crush improved erectile function, promoted nerve regeneration, and prevented fibrosis of the corpus cavernosum following $\mathrm{CN}$ injury.
\end{abstract}

(C) 2012 European Association of Urology. Published by Elsevier B.V. All rights reserved.

* Corresponding author. Department of Urology, University of California, San Francisco, CA 94143-0738, USA. Tel. +1 415476 1611; Fax: +1 4154768849.

E-mail address: tlue@urology.ucsf.edu (T.F. Lue). 


\section{Introduction}

Radical prostatectomy (RP) is considered the gold standard for the treatment of clinically localized prostate cancer, with excellent long-term oncologic results [1]. Despite the advantages of nerve-sparing techniques and laparoscopic and robot-assisted surgery, erectile dysfunction(ED) remains a frequent complication of RP [2,3]. Phosphodiesterase type 5 inhibitors are commonly used to treat ED after RP, but their efficacy has been disappointing for many ED patients after RP $[4,5]$. Therefore, there is an urgent need to develop novel and effective strategies for the treatment of ED after RP.

Adipose tissue has been suggested as an attractive and abundant stem cell source [6]. Similar to bone marrow mesenchymal stem cells, adipose-derived stem cells (ADSCs) are multipotent, self-renewing cells with the potential to differentiate into several cell types [7-9]. In addition, it has been demonstrated that ADSCs are capable of secreting multiple growth factors and cytokines [10]. Intracavernous injection of cultured ADSCs has been shown to improve erectile function and result in preservation of the corpus cavernosum microstructure in rat models of ED associated with hyperlipidemia [11], diabetes mellitus [12], and cavernous nerve (CN) injury [13].

Most types of adult stem cells require isolation and expansion in vitro to obtain cell numbers adequate for achieving beneficial effects [14]. ADSCs are isolated from the stromal vascular fraction (SVF) of adipose tissue and cultureexpanded in various conditions [15]. The risks of xenogenic nutritional sources, microbial contamination, and tumorigenesis during cell culture raise concerns regarding implantation of these cultured stem cells into human subjects [16]. To avoid these risks, SVF isolation and administration without culturing has been proposed as an easier and safer way to use stem and progenitor cells in adipose tissue for treatment. Human clinical trials have recently been initiated that use injection of SVF during breast reconstruction surgery and to treat myocardial infarction, traumatic calvarial defects, lipodystrophy, and type 1 and 2 diabetes [17].

Another caveat of previous studies using ADSCs for the treatment of ED was administration at the time of CN injury. However, to serve as a treatment for nerve regeneration in humans, it would be more desirable to administer the agent at a later time point after injury, when it becomes clearer which patient population would benefit most from treatment (ie, those developing ED after nerve-sparing prostatectomy). We hypothesized that SVF is effective in improving erectile function following $\mathrm{CN}$ injury. The aim of this study was to examine the therapeutic effects of immediate and delayed treatment with intracavernous injection of uncultured autologous adipose-derived SVF on erectile function and corpus cavernosum microstructure in a rat model of $\mathrm{CN}$ injury.

\section{Materials and methods}

\subsection{Study design}

Eighty-nine Sprague Dawley rats (12 wk old) were obtained from Charles River Laboratories (Wilmington, MA, USA). Sixty-three rats underwent bilateral $\mathrm{CN}$ crush injury and were randomly divided into three groups: intracavernous injection of saline (vehicle; $n=23$ ), intracavernous injection of SVF immediately after CN crush (immediate treatment; $n=17$ ), and intracavernous injection of SVF $4 \mathrm{wk}$ after CN crush (delayed treatment; $n=23$ ). The remaining rats underwent sham surgery (sham; $n=26$ ). Twelve weeks after $\mathrm{CN}$ crush or sham surgery, all rats underwent erectile function measurement. Thereafter, they were sacrificed, and penile tissue was harvested for histologic analysis. All procedures were approved by the Institutional Animal Care and Use Committee at the University of California, San Francisco. All functional tests and histologic assessments were performed in a strictly blinded fashion.

\subsection{Cavernous nerve injury}

Under isoflurane anesthesia, the major pelvic ganglion (MPG) and CN were exposed on both sides of the prostate via a midline laparotomy. No further manipulation occurred in the sham group, while bilateral $\mathrm{CN}$ crush injury was performed as described previously in all other groups [13].

\subsection{Isolation of stromal vascular fraction}

During the same surgery or 4 wk after CN injury, perigonadal adipose tissue was harvested in all rats. Adipose tissue was washed with sterile saline and minced, followed by enzymatic digestion with Adipase (Tissue Genesis, Honolulu, HI, USA) at $37^{\circ} \mathrm{C}$ for $30 \mathrm{~min}$. The cells were then washed and centrifuged, and the pellet was resuspended in saline. The nucleated cells from the pellet were counted with an automated cell counter and diluted to 5000 cells per microliter in saline.

\subsection{Intracavernous injection of stromal vascular fraction}

Under isoflurane anesthesia, a skin incision was made to expose the penis, and either $400 \mu \mathrm{l}$ SVF solution (5000 cells per microliter) or $400 \mu \mathrm{l}$ saline was injected into the corpus cavernosum with a 25 -gauge needle. An elastic band was placed at the base of the penis immediately before injection and was removed 3 min after injection.

\subsection{Erectile function evaluation}

Intracavernous pressure (ICP) response to electrostimulation of the $\mathrm{CN}$ was used to evaluate erectile function [18]. Briefly, under ketamine (100 mg/kg) and midazolam $(5 \mathrm{mg} / \mathrm{kg}$ ) anesthesia, the CNs were exposed via midline laparotomy. The corpus cavernosum was cannulated with a heparinized (200 U/ml) 25-gauge needle connected to a pressure transducer (Utah Medical Products, Midvale, UT, USA). The stimulus parameters were $1.5 \mathrm{~mA}, 20 \mathrm{~Hz}$, pulse width of $0.2 \mathrm{~ms}$, and duration of $50 \mathrm{~s}$. The maximum increase of ICP of three stimuli per side was selected for statistical analysis in each animal. Mean arterial blood pressure (MAP) was recorded using a 25 -gauge needle inserted into the aortic bifurcation [13,18].

\subsection{Histology}

The penile midshaft was harvested and fixed with $2 \%$ formaldehyde and $0.002 \%$ picric acid in 0.1-M phosphate buffer saline (PBS) for $4 \mathrm{~h}$, followed by immersion in $30 \%$ sucrose in PBS overnight at $4{ }^{\circ} \mathrm{C}$. Tissues were embedded into optimal cutting temperature compound (Sakura Finetek, Torrance, CA, USA). Sections were cut at a thickness of $5 \mu \mathrm{m}$.

Immunohistochemical staining was performed according to a previously described protocol [18]. The primary antibodies included rabbit antineuronal nitric oxide synthase (nNOS; 1:100; Santa Cruz Biotechnologies, Santa Cruz, CA, USA) and mouse antineurofilament (NF; 1:500; this antibody was obtained from the developmental Studies Hybridoma Bank, developed under the auspices of the National Institute of Child Health and Human Development and maintained by the 

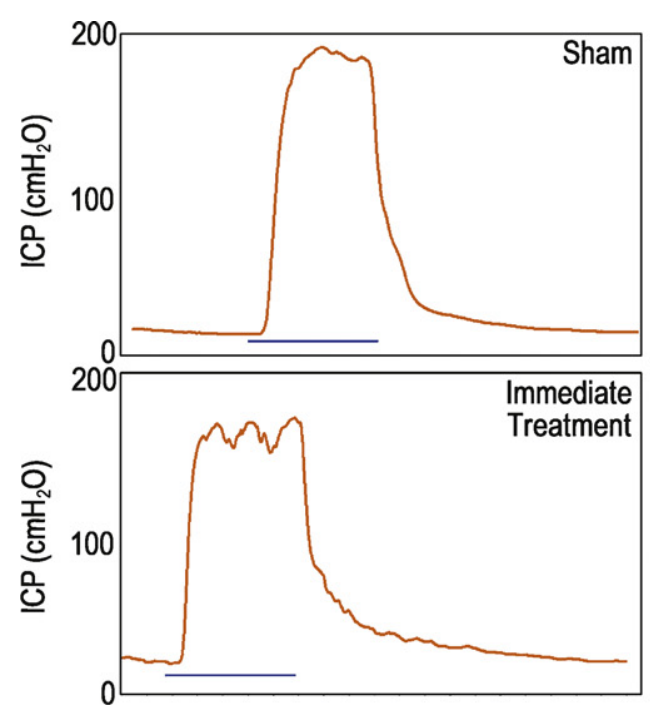
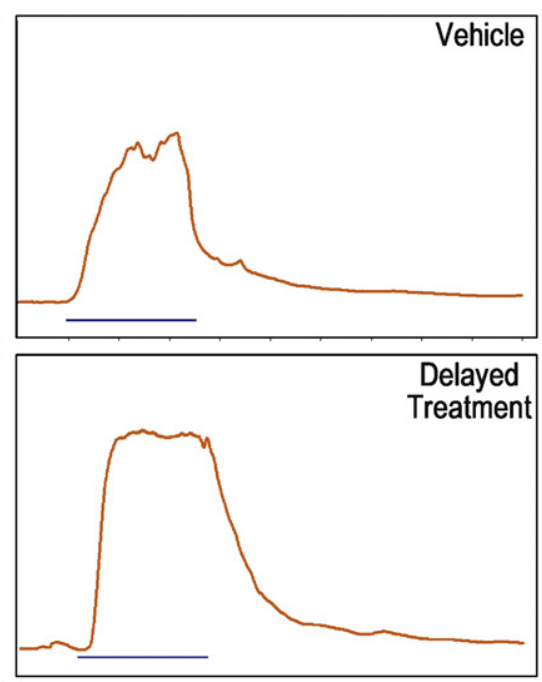

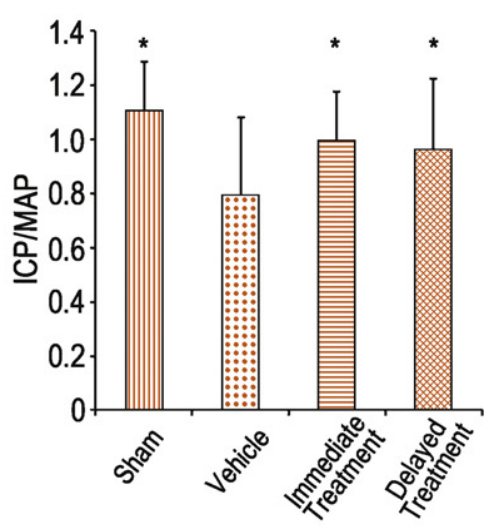

Fig. 1 - Electrostimulation of cavernous nerves $(\mathrm{CN})$ at 12 wk. (a) Representative intracavernous pressure (ICP) recording of each experimental group. The black curve represents ICP values in response to $\mathrm{CN}$ stimulation. The red bar represents 50 -s electrical stimulation of the $\mathrm{CN}$. (b) The effect of stromal vascular fraction treatment in improving the ICP-to- mean arterial pressure ratio.

ICP = intracavernous pressure; MAP = mean arterial pressure.

${ }^{*} \boldsymbol{p}<0.05$ compared with vehicle group.

University of Iowa, Department of Biology, Iowa City, IA, USA). Actin was stained by incubation with Alexa-488-conjugated phalloidin (1:400; Invitrogen, Carlsbad, CA, USA) for $20 \mathrm{~min}$ at room temperature. The secondary antibodies used included Alexa-488- and Alexa-594conjugated antibodies (1:500; Invitrogen). Nuclei were stained with 4',6-diamidino-2-phenylindole (DAPI; Invitrogen).

Masson's trichrome staining procedures were performed according to a previously described protocol [19]. Image analysis was performed by computerized densitometry using Image-Pro Plus 5.1 (Media Cybernetics, Silver Spring, MD, USA). To quantify smooth muscle, the percentage of f-actin bright positive area within the corpus cavernosum was analyzed. Masson's trichrome staining was used to quantify the ratio between smooth muscle and collagen within the corpus cavernosum. For nNOS and NF staining, the ratio between nNOS or NF positive area and total dorsal nerve area was calculated.

\subsection{Statistical analysis}

The results were analyzed using GraphPad Prism v.4 software (GraphPad Software, La Jolla, CA, USA) and expressed as mean plus or minus standard deviation. Multiple groups were compared using one-way analysis of variance followed by the Tukey-Kramer test for post hoc comparisons. Statistical significance was set at $p<0.05$.

\section{Results}

3.1. Stromal vascular fraction treatment improves erectile function after cavernous nerve injury

$\mathrm{CN}$ injury consistently resulted in decreased erectile function compared to sham animals (Fig. 1). Recovery of erectile function was observed in both SVF-treated groups, as reflected by a significantly increased ICP/MAP response to $\mathrm{CN}$ electrostimulation compared to the vehicle group. There was no significant difference between the immediatetreatment group and the delayed-treatment group.

\subsection{Histologic data}

\subsubsection{Stromal vascular fraction treatment promotes nerve} regeneration

Examination of nNOS and NF contents revealed nerve injury in the vehicle group, as illustrated by a significant decrease of positive immunostaining compared to the sham group (Figs. 2 and 3; Table 1). Following SVF treatment immediately

Table 1 - Neuronal nitric oxide synthase, neurofilament, actin, and Masson's trichrome staining data in each experimental group*

\begin{tabular}{|c|c|c|c|c|}
\hline Group & $\begin{array}{l}\text { nNOS content } \\
\text { in dorsal nerve, \% }\end{array}$ & $\begin{array}{l}\text { NF content in } \\
\text { dorsal nerve, \% }\end{array}$ & $\begin{array}{l}\text { SM content in } \\
\text { corpus cavernosum, \% }\end{array}$ & $\begin{array}{l}\text { Ratio between SM and } \\
\text { collagen in corpus cavernosum }\end{array}$ \\
\hline Sham & $1.46 \pm 0.39^{* *}$ & $14.64 \pm 2.36^{* *}$ & $5.67 \pm 1.05^{* *}$ & $0.089 \pm 0.0224^{* *}$ \\
\hline Vehicle & $0.77 \pm 0.24$ & $8.4 \pm 2.08$ & $3.57 \pm 0.69$ & $0.0445 \pm 0.0182$ \\
\hline Immediate & $1.19 \pm 0.25^{* *}$ & $12.62 \pm 2.62^{* *}$ & $4.72 \pm 0.061^{* *}$ & $0.0714 \pm 0.0098^{* *}$ \\
\hline Delayed & $1.08 \pm 0.25^{* *}$ & $13.12 \pm 2.21^{* *}$ & $4.51 \pm 0.67^{* *}$ & $0.0701 \pm 0.0166^{* *}$ \\
\hline \multicolumn{5}{|c|}{$\begin{array}{l}\text { nNOS = neuronal nitric oxide synthase; NF = neurofilament; SM = smooth muscle. } \\
{ }^{*} \text { Histomorphometric digital analysis was performed on each tissue section of the rat penis. nNOS and NF were expressed as a percentage of the nNOS- or NF- } \\
\text { positive area in the dorsal nerve area. SM was expressed as a percentage of the actin-positive area within the corpus cavernosum. The ratio between SM and } \\
\text { collagen within the corpus cavernosum was analyzed for Masson's trichrome staining. } \\
{ }^{*} p<0.05 \text { compared with vehicle group. }\end{array}$} \\
\hline
\end{tabular}



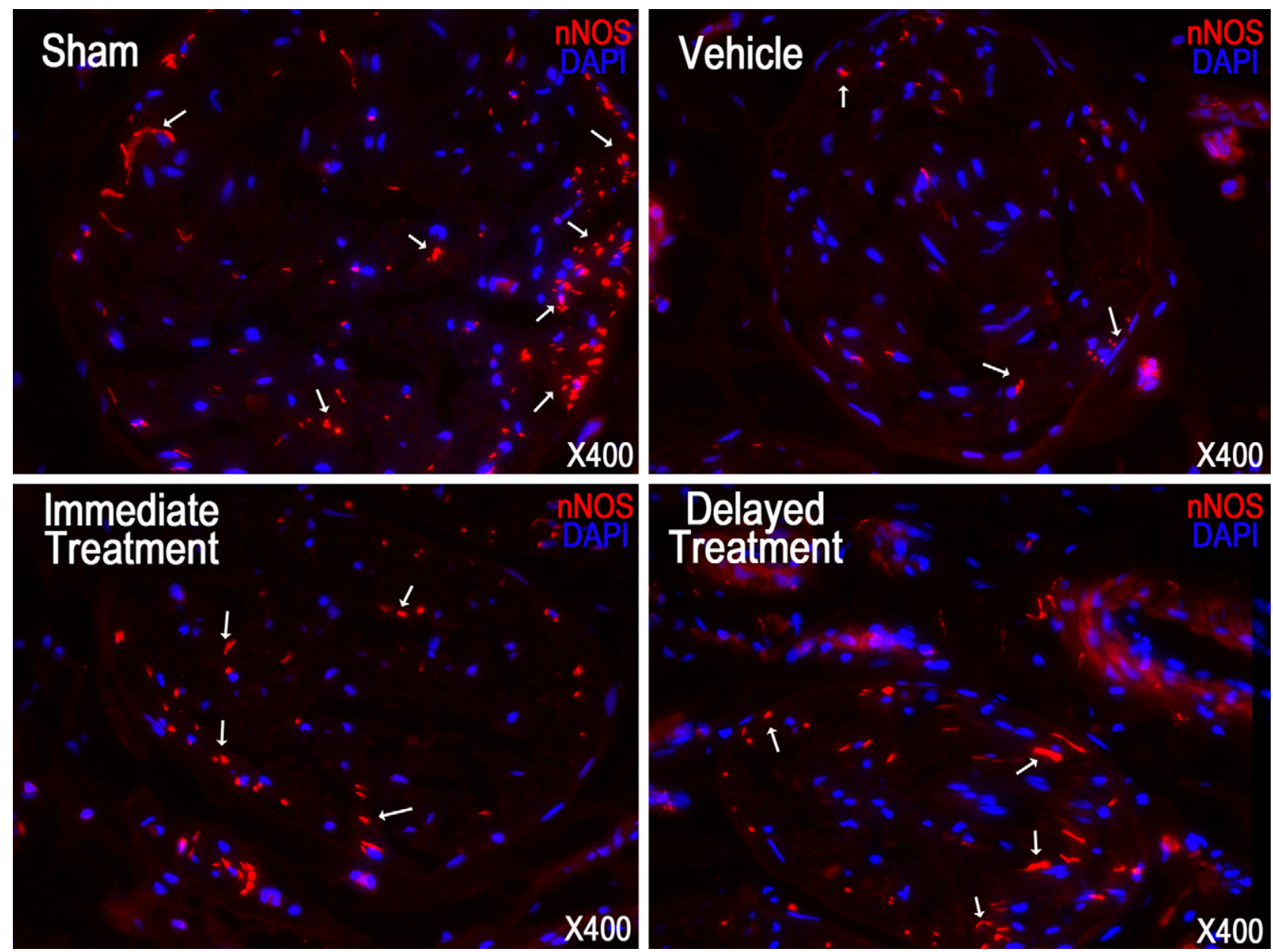

Fig. 2 - Neuronal nitric oxide synthase (nNOS) staining in a penile midshaft specimen. Representative images of nNOS-positive fibers in penile dorsal nerve of each experimental group are presented. NNOS-positive fibers were stained red (arrow) in the dorsal nerve. Original magnification is $\times 400$. nNOS = neuronal nitric oxide synthase; DAPI = 4',6-diamidino-2-phenylindole.

or 4 wk after $\mathrm{CN}$ crush, the number of nNOS containing fibers as well as the total axonal content (NFs) were significantly higher in both groups compared to the vehicle group. There was no significant difference between the immediate and delayed treatments.

3.2.2. Stromal vascular fraction treatment improves cavernosal smooth muscle content

A significantly decreased smooth muscle content and smooth muscle-to-collagen ratio within the corpus cavernosum in the vehicle group compared to the sham group revealed the development of corpus cavernosum fibrosis following $\mathrm{CN}$ injury (Fig. 4; Table 1). Both SVF treatments partially but significantly restored the smooth muscle content and reduced fibrosis. Again, no significant difference was noted when SVF was administered immediately versus delayed.

\section{Discussion}

Cell culture expansion of stem cells is often required to reach sufficient cell numbers for therapeutic purposes. However, current major restrictions regarding the use of cultured cells in human subjects include contamination, unexpected cell differentiation, and tumorigenesis [20]. Unlike other stem cells that are present in low concentrations in their native tissues, ADSCs have been shown to be abundantly present in adipose tissue [21]. Most importantly, compared to other stem cell sources such as bone marrow, large amounts of adipose tissue can be harvested with minimal or no side effects from human subjects, providing a new perspective on using adipose tissue-derived cells in the clinical setting. Adipose tissue is composed of two main cell populations: mature adipocytes and the SVF. SVF is a heterogeneous fraction containing preadipocytes, mature endothelial cells, vascular smooth muscle cells, macrophages, fibroblasts, and a large population of stem/progenitor cells [15,22].

In the present study, SVF was isolated from adipose tissue and injected intracavernously into rats after $\mathrm{CN}$ injury. Compared to previous studies in this setting, there was notable spontaneous nerve regeneration in untreated animals [18,23], likely the result of the long time interval between nerve injury and evaluation. However, this nerve regeneration was significantly improved by SVF injection. It can be speculated that the stem/progenitor cells in the SVF 

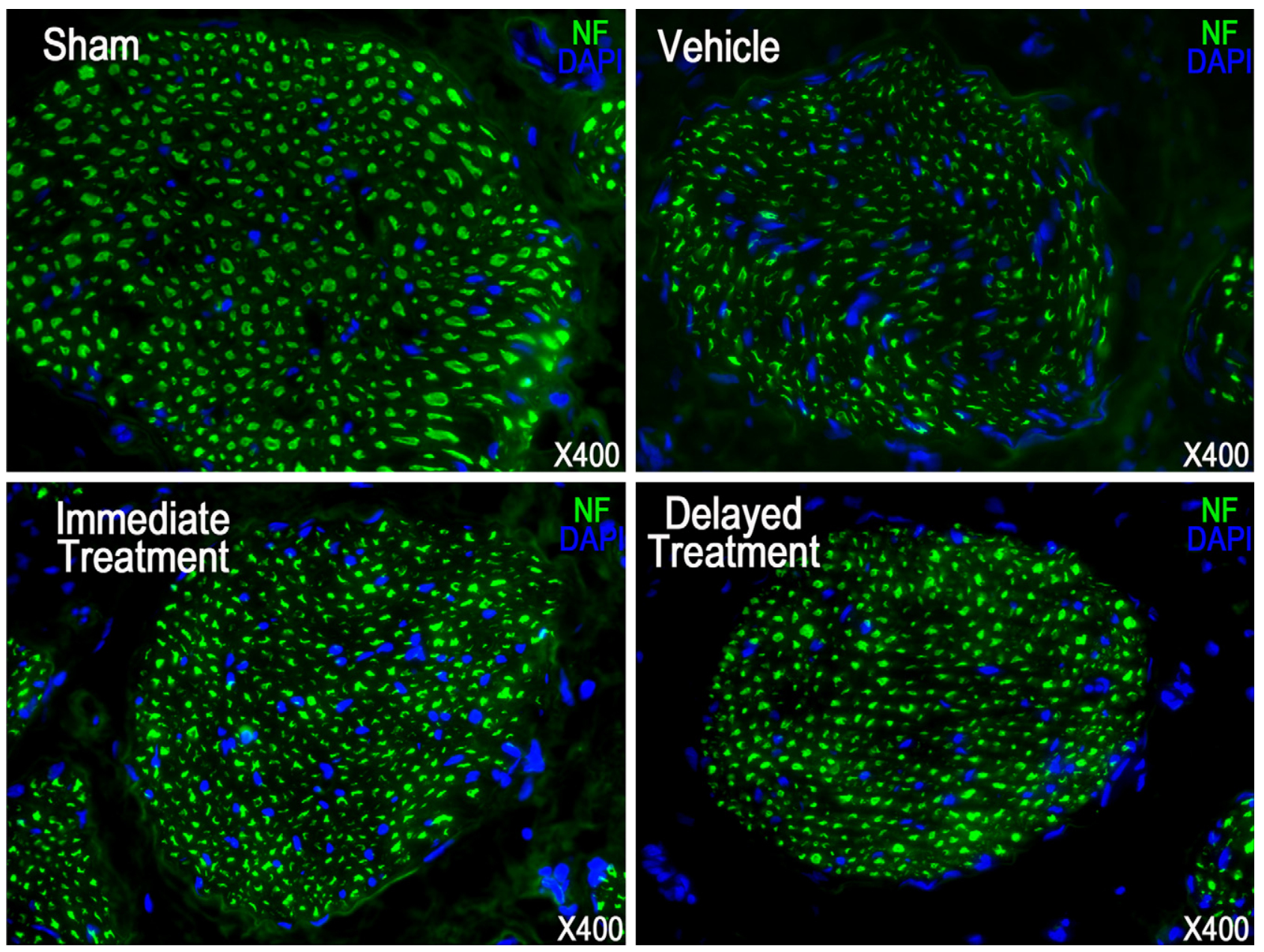

Fig. 3 - Neurofilament (NF) staining in a penile midshaft specimen. Representative images are presented for NF-positive fibers in penile dorsal nerve of each experimental group. Original magnification is $\times 400$.

$\mathrm{NF}$ = neurofilament; DAPI = 4',6-diamidino-2-phenylindole.

provided the therapeutic effect and preserved erectile function of $\mathrm{CN}$-injured rats by producing pro-survival, antiapoptotic, and neurotrophic factors [24,25]. We have confirmed these neuroregenerative processes of ADSC in previous studies in which early migration of ADSC toward the MPG was observed [19].

This is the first study to examine the effects of stem cell treatment for ED in a chronic state after nerve trauma. Functional recovery and penile histologic improvement were observed when treatment was delayed by $4 \mathrm{wk}$, when neurodegeneration and end-organ damage, including fibrosis, have occurred. The effects of the delayed administration of SVF are in agreement with results from stem cell studies in the central nervous system. Direct injection of bone marrow stromal cells in the brain 2 mo after traumatic brain injury have resulted in neuroregeneration [26]. In addition, systemic injection of umbilical tissue-derived cells in a similar brain injury model resulted in locally increased vascular density and decreased apoptosis, thus supporting functional recovery [27]. In the present study, we found decreased fibrosis in the corpus cavernosum. Whether this effect is secondary to reinnervation and reoxygenation of the corpus cavernosum or the result of local interaction between stem cells and the extracellular matrix remains undetermined. It has previously been shown that ADSCs produce matrix-metalloproteinases that may aid in reducing deposited collagen following corpus cavernosum denervation [28]. That said, it has also been shown that ADSCs migrate away from the corpus cavernosum early after injection [19].

We believe that this study bridges an important gap in translating the results of previous ADSC studies toward the clinical setting and application in human subjects. In the current age, SVF is being used in various clinical trials and has been proven safe and effective in various settings [17]. With the observation of the beneficial effects of SVF replicating those of ADSCs, a novel approach that is directly applicable in the clinical setting has been identified, and initial clinical studies can now be expected within a short time frame. Liposuction and injection of SVF during the same procedure as RP may be a reasonable treatment option for preoperatively motivated patients. Furthermore, the 

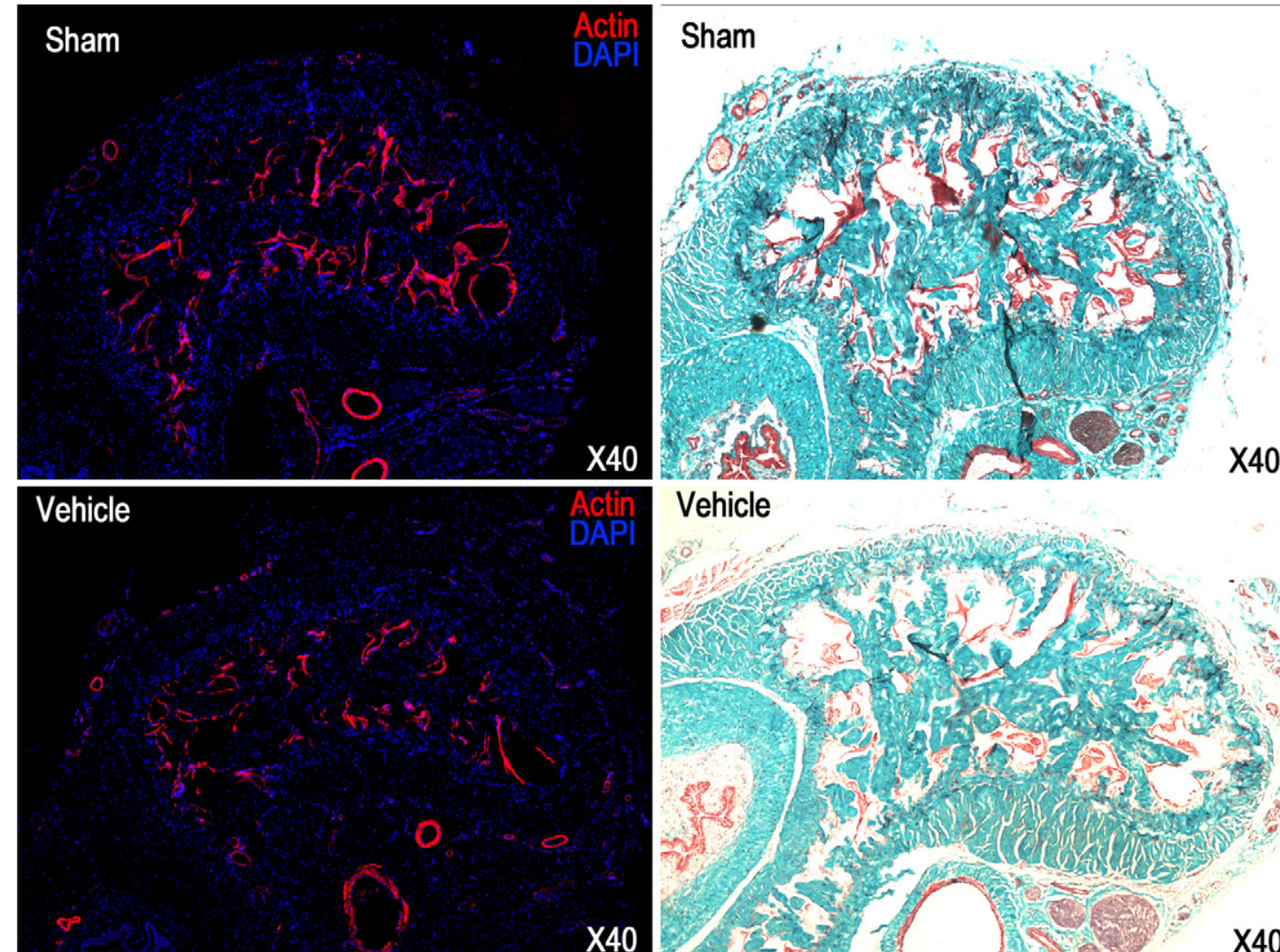

\section{Vehicle}
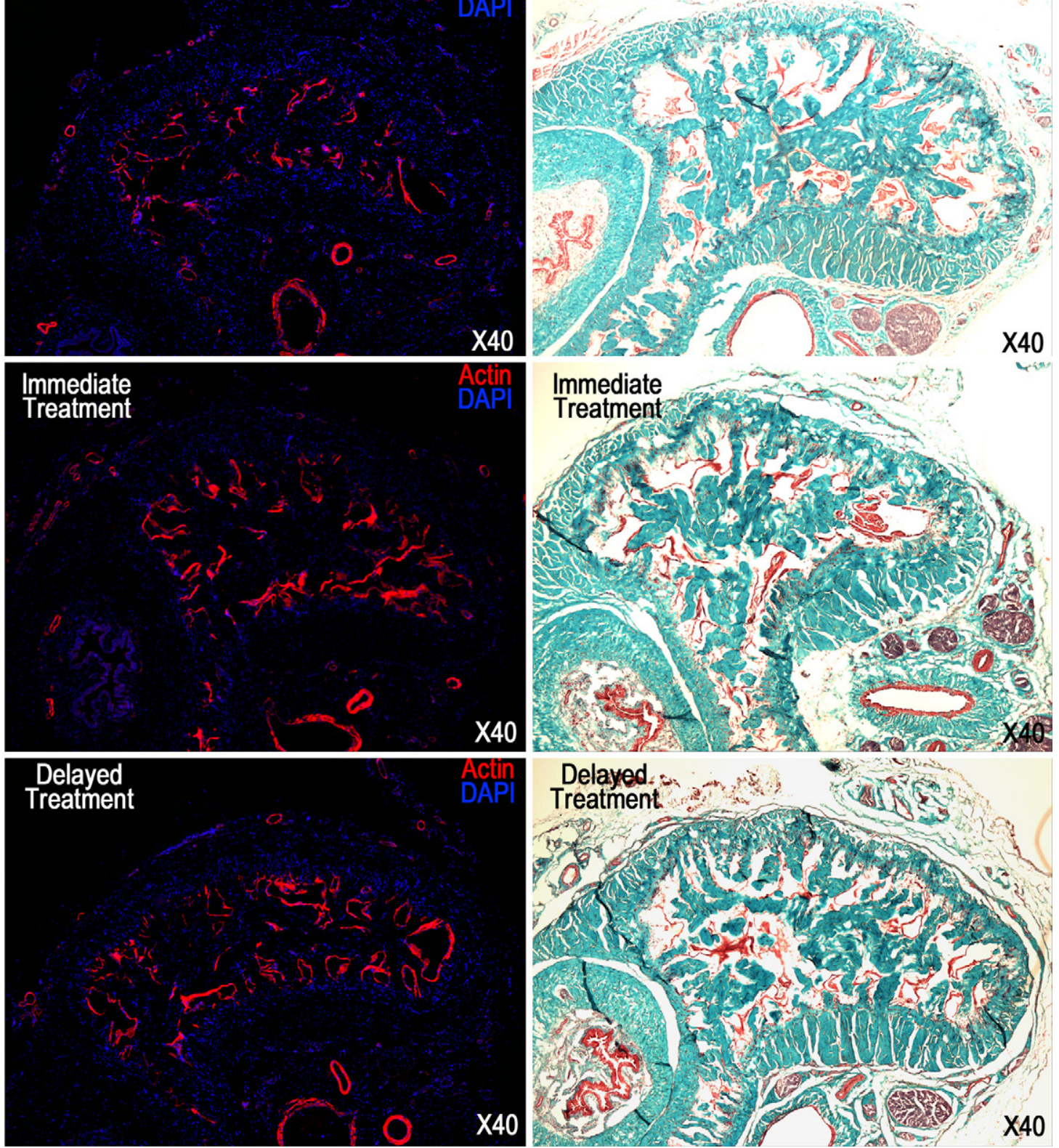

Fig. 4 - Masson's trichrome and phalloidin staining in a penile midshaft specimen. (a) Representative images of actin staining of each experimental group. Smooth muscle in corpus cavernosum was stained red. Original magnification is $\times \mathbf{4 0}$. (b) Representative images of Masson's trichrome staining of each experimental group. Smooth muscle and connective tissue are stained red and green, respectively. Original magnification is $\times 40$. DAPI = 4',6-diamidino-2-phenylindole. 
positive results of delayed treatment imply that treatment can also be given several weeks following prostatectomy at the time patients begin attempting sexual intercourse.

There are some important limitations to this study. First, ICP/MAP values exceeding 1 were noted in few rats, which may appear supraphysiologic. However, ICP can be raised to several hundred $\mathrm{mmHg}$ if both the cavernous and pudendal nerves are stimulated [29]. This outcome may happen during stimulation when the current spreads to the pudendal efferent nerve fibers because of the scars around the MPG and CNs. The prolonged observation time after injury may have allowed for more extensive scar development. Second, the exact composition of the rat SVF was not examined in this study. However, it is likely that the cell elements in the SVF of the rat are comparable to those in human SVF [30]. Third, we have not determined whether the decreased fibrosis in the corpus cavernosum is the result of a direct interaction between ADSC and the extracellular matrix or whether this is the result of increased innervation of the corpus cavernosum. Further research is ongoing to determine these interactions and to further understand the effects of cellular therapies in ED following $\mathrm{CN}$ injury.

\section{Conclusions}

Autologous SVF injected immediately or $4 \mathrm{wk}$ after $\mathrm{CN}$ crush improved erectile function, promoted nerve regeneration, and prevented fibrosis of the corpus cavernosum following $\mathrm{CN}$ injury. The clinical availability of routine SVF isolation devices merits the study of autologous SVF therapy in penile rehabilitation following RP in the near future.

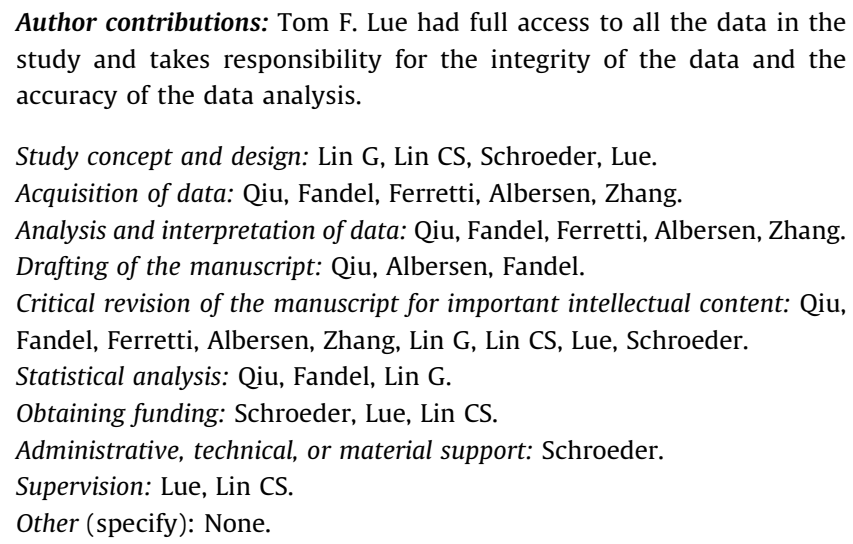
study and takes responsibility for the integrity of the data and the accuracy of the data analysis.

Study concept and design: Lin G, Lin CS, Schroeder, Lue. Acquisition of data: Qiu, Fandel, Ferretti, Albersen, Zhang.

Analysis and interpretation of data: Qiu, Fandel, Ferretti, Albersen, Zhang. Drafting of the manuscript: Qiu, Albersen, Fandel.

Critical revision of the manuscript for important intellectual content: Qiu, Fandel, Ferretti, Albersen, Zhang, Lin G, Lin CS, Lue, Schroeder.

Statistical analysis: Qiu, Fandel, Lin G.

Obtaining funding: Schroeder, Lue, Lin CS.

Administrative, technical, or material support: Schroeder.

Supervision: Lue, Lin CS.

Other (specify): None.

Financial disclosures: I certify that all conflicts of interest, including specific financial interests and relationships and affiliations relevant to the subject matter or materials discussed in the manuscript (eg, employment/ affiliation, grants or funding, consultancies, honoraria, stock ownership or options, expert testimony, royalties, or patents filed, received, or pending), are the following: Tania Schroeder is an employee of and Tom F. Lue is a consultant for American Medical Systems.

Funding/Support and role of the sponsor: The study was supported by departmental funding and a grant from American Medical Systems.

Acknowledgment statement: The authors thank Robert Lund and Linda Mummah-Schendel for their contributions to this study. MA is a fellow of the Research Foundation-Flanders (FWO).

\section{References}

[1] Heidenreich A, Bellmunt J, Bolla M, et al. EAU guidelines on prostate cancer. Part 1: screening, diagnosis, and treatment of clinically localised disease. Eur Urol 2011;59:61-71.

[2] Dubbelman YD, Dohle GR, Schröder FH. Sexual function before and after radical retropubic prostatectomy: a systematic review of prognostic indicators for a successful outcome. Eur Urol 2006;50:711-20.

[3] Walz J, Burnett AL, Costello AJ, et al. A critical analysis of the current knowledge of surgical anatomy related to optimization of cancer control and preservation of continence and erection in candidates for radical prostatectomy. Eur Urol 2010;57:179-92.

[4] Kendirci M, Hellstrom WJ. Current concepts in the management of erectile dysfunction in men with prostate cancer. Clin Prostate Cancer 2004;3:87-92.

[5] Hatzimouratidis K, Burnett AL, Hatzichristou D, McCullough AR, Montorsi F, Mulhall JP. Phosphodiesterase type 5 inhibitors in postprostatectomy erectile dysfunction: a critical analysis of the basic science rationale and clinical application. Eur Urol 2009;55:334-47.

[6] Lindroos B, Suuronen R, Miettinen S. The potential of adipose stem cells in regenerative medicine. Stem Cell Rev 2011;7:269-91.

[7] Lin GT, Banie L, Ning HX, Bella AJ, Lin CS, Lue TF. Potential of adipose-derived stem cells for treatment of erectile dysfunction. J Sex Med 2009;6:320-7.

[8] Ning HX, Liu G, Lin GT, Yang R, Lue TF, Lin CS. Fibroblast growth factor 2 promotes endothelial differentiation of adipose tissuederived stem cells. J Sex Med 2009;6:967-79.

[9] Zuk PA, Zhu M, Ashjian P, et al. Human adipose tissue is a source of multipotent stem cells. Mol Biol Cell 2002;13:4279-95.

[10] Salgado AJ, Reis RL, Sousa NJ, Gimble JM. Adipose tissue derived stem cells secretome: soluble factors and their roles in regenerative medicine. Curr Stem Cell Res Ther 2010;5:103-10.

[11] Huang YC, Ning HX, Shindel AW, et al. The effect of intracavernous injection of adipose tissue-derived stem cells on hyperlipidemiaassociated erectile dysfunction in a rat model. J Sex Med 2010;7: 1391-400.

[12] Garcia MM, Fandel TM, Lin G, et al. Treatment of erectile dysfunction in the obese type 2 diabetic ZDF rat with adipose tissuederived stem cells. J Sex Med 2010;7:89-98.

[13] Albersen M, Fandel TM, Lin G, et al. Injections of adipose tissuederived stem cells and stem cell lysate improve recovery of erectile function in a rat model of cavernous nerve injury. J Sex Med 2011;7: 3331-40.

[14] Zhang H, Albersen M, Jin X, Lin G. Stem cells: novel players in the treatment of erectile dysfunction. Asian J Androl 2012;14:145-55.

[15] Lin G, Garcia M, Ning H, et al. Defining stem and progenitor cells within adipose tissue. Stem Cells Dev 2008;17:1053-63.

[16] Ning H, Liu G, Lin G, et al. Identification of an aberrant cell line among human adipose tissue-derived stem cell isolates. Differentiation 2009;77:172-80.

[17] Casteilla L, Planat-Benard V, Laharrague P, Cousin B. Adiposederived stromal cells: their identity and uses in clinical trials, an update. World J Stem Cells 2011;3:25-33.

[18] Albersen M, Fandel TM, Zhang H, et al. Pentoxifylline promotes recovery of erectile function in a rat model of postprostatectomy erectile dysfunction. Eur Urol 2011;59:286-96.

[19] Fandel TM, Albersen M, Lin G, et al. Recruitment of intracavernously injected adipose-derived stem cells to the major pelvic ganglion improves erectile function in a rat model of cavernous nerve injury. Eur Urol 2012;61:201-10.

[20] Gimble JM, Bunnell BA, Chiu ES, Guilak F. Concise review: adiposederived stromal vascular fraction cells and stem cells: let's not get lost in translation. Stem Cells 2011;29:749-54.

[21] Housman TS, Lawrence N, Mellen BG, et al. The safety of liposuction: results of a national survey. Dermatol Surg 2002;28:971-8. 
[22] Fraser JK, Wulur I, Alfonso Z, Hedrick MH. Fat tissue: an underappreciated source of stem cells for biotechnology. Trends Biotechnol 2006;24:150-4.

[23] Kendirci M, Trost L, Bakondi B, Whitney MJ, Hellstrom WJ, Spees JL. Transplantation of nonhematopoietic adult bone marrow stem/ progenitor cells isolated by p75 nerve growth factor receptor into the penis rescues erectile function in a rat model of cavernous nerve injury. J Urol 2010;184:1560-6.

[24] Wei X, Zhao L, Zhong J, et al. Adipose stromal cells-secreted neuroprotective media against neuronal apoptosis. Neurosci Lett 2009;462:76-9.

[25] Rehman J, Traktuev D, Li JL, et al. Secretion of angiogenic and antiapoptotic factors by human adipose stromal cells. Circulation 2004;109:1292-8.

[26] Xiong Y, Qu C, Mahmood A, et al. Delayed transplantation of human marrow stromal cell-seeded scaffolds increases transcallosal neural fiber length, angiogenesis, and hippocampal neuronal survival and improves functional outcome after traumatic brain injury in rats. Brain Res 2009;31:183-91.

[27] Zhang L, Li Y, Zhang C, Chopp M, Gosiewska A, Hong K. Delayed administration of human umbilical tissue-derived cells improved neurological functional recovery in a rodent model of focal ischemia. Stroke 2011;42:1437-44.

[28] Kachgal S, Putnam AJ. Mesenchymal stem cells from adipose and bone marrow promote angiogenesis via distinct cytokine and protease expression mechanisms. Angiogenesis 2011;14:47-59.

[29] Lue TF, Takamura T, Schmidt RA, Palubinskas AJ, Tanagho EA. Hemodynamics of erection in the monkey. J Urol 1983;130:1237-41.

[30] Lin SD, Huang SH, Lin YN, et al. Engineering adipose tissue from uncultured human adipose stromal vascular fraction on collagen matrix and gelatin sponge scaffolds. Tissue Eng Part A 2011;17: 1489-98.

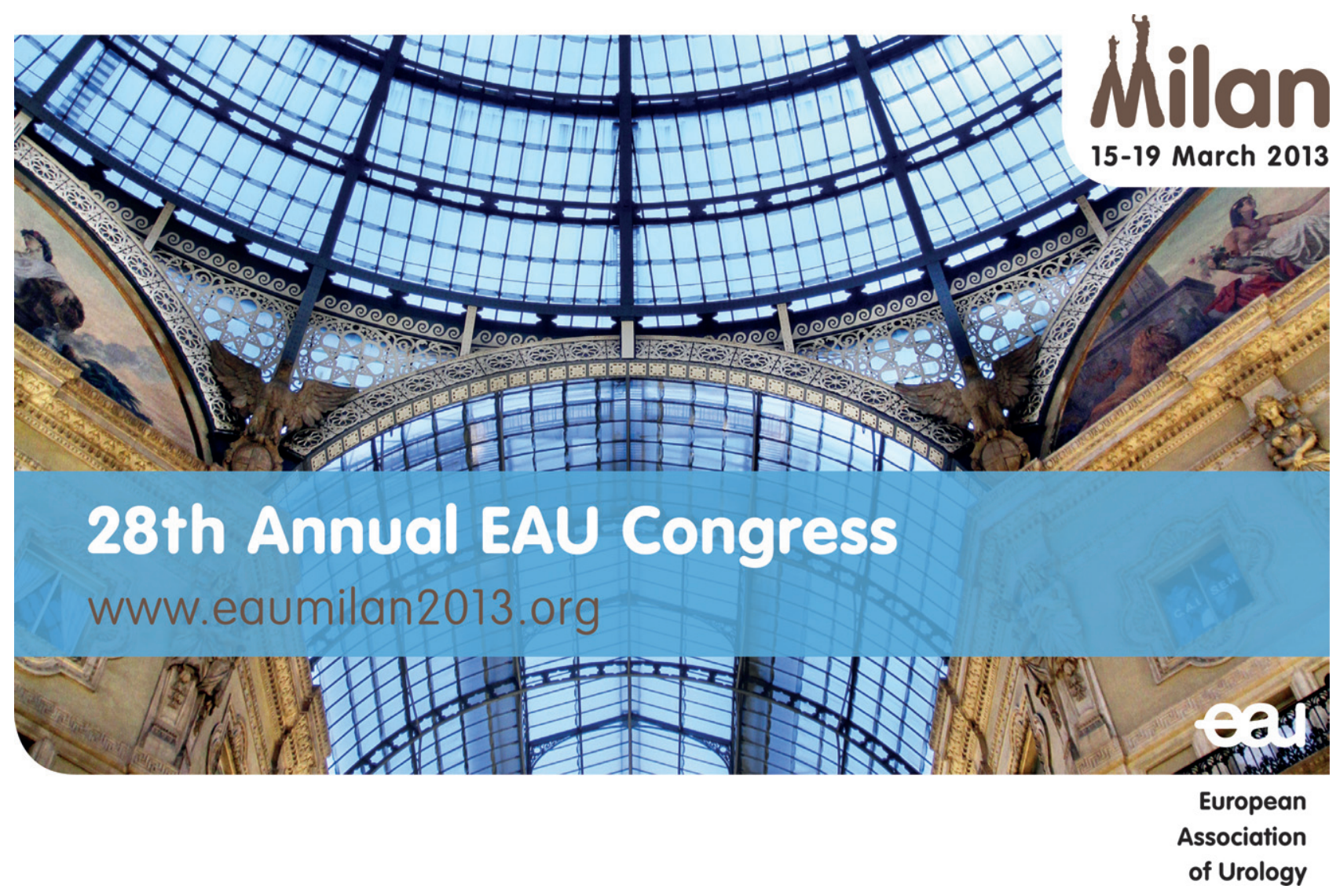

